\title{
İnce dişeti fenotipinde koruma için serbest dişeti grefti uygulaması: Vaka raporu
}

\author{
Free gingival graft application for preservation in thin gingival phenotype: Case report \\ (D) Mustafa Atalay ${ }^{1}$, DCüneyt Asım Aral ${ }^{1}$
}

${ }^{1}$ İnönü Üniversitesi, Diş Hekimliği Fakültesi, Periodontoloji Anabilim Dalı, Malatya, Türkiye

\section{ÖZET}

Keratinize dişetinin $2 \mathrm{~mm}$ altında olması durumunda müdahele edilip edilmemesi konusunda görüş ayrılıkları mevcuttur. Dişeti çekilmesi, ince dişeti fenotipi, kök çıkıntıları gibi lokal problemler ise dişeti ogmentasyon prosedürlerini endike duruma getirebilmektedir. Bu vaka raporunda alt anterior bölgede köklerinin belirgin olması şüphesiyle kliniğimize başvuran hastaya yetersiz keratinize dişeti ve ince dişeti fenotipi varlığı nedeniyle yapılan serbest dişeti grefti operasyonu anlatılmaktadır. Ameliyatta önce alıcı bölge hazırlandı. Ardından palatinal bölgeden alınan serbest dişeti grefti alıcı bölgeye adapte edildi. Birinci haftada süturlar alındı ve iyileşmede problem olmadığı gözlendi. Yapılan kontrollerde dokunun çevre dokularla uyumunun artığı ve yeterli keratinize dişeti varlığı gözlendi. Keratinize dişeti miktarını artırma operasyonlarının gerekliliği konusunda ise daha ileri çalışmalara intiyaç vardır.

Anahtar kelimeler: diş eti çekilmesi; diş eti hastalıkları; oral cerrahi işlemleri

\section{ABSTRACT}

There are different opinions on whether to intervene if the keratinized gingiva is below $2 \mathrm{~mm}$. Local problems such as gingival recession, thin gingival phenotype, root protrusions may make gingival augmentation procedures indicated. In this case report, free gingival graft operation performed due to the presence of insufficient keratinized gingiva and thin gingival phenotype is described in a patient who applied to our clinic with the suspicion of a prominent root in the lower anterior region. In the surgery, the recipient site was first prepared. Then, the free gingival graft taken from the palatal region was adapted to the recipient site. One week later, sutures were removed and it was observed that there was no problem in healing. Graft compatibility increased and adequate keratinized gingiva was present in the follow-up sessions. Further studies are needed on the necessity of operations to increase the amount of keratinized gingiva.

Keywords: gingival recession; gingival diseases; oral surgical procedures

\section{Giriş}

Uzun yıllar boyunca yeterli miktarda dişeti varlığı periodontal sağlık için anahtar olarak düşünülmüştür (Nevins M, Nevins ML, Kim, Schupbach \& Kim, 2011). Lang ve Löe yaptıkları çalışmada $2 \mathrm{~mm}$ ve altında keratinize dişeti varlığında bütün diş yüzeylerinde plak bulunmasa dahi, dişetinde inflamasyon ve çeşitli miktarlarda eksudasyon gözlendiğini belirtmişlerdir (Lang \& Löe, 1972). Bazı diğer araştırmacılar ise bu bağlantının doğru olmadığını, keratinize dişetinin azaldığı hatta olmadığı durumlarda da periodontal sağlığın sağlanabileceğini belirtmişlerdir (Lindhe \& Wennström, 1983; Miyasato, Crigger \& Egelberg, 1977). Fakat dişeti çekilmesi, ince periodonsiyum ve kök çıkıntıları gibi lokal problemler dişeti ogmentasyonu yapılmasını gerektirebilir (Agarwal, Tarun Kumar \& Mehta, 2015; Carlos, Muyco, Caliwag, Fajardo \& Uy, 1995). Sağlıklı keratinize dişeti fırçalama nedeniyle oluşabilecek fiziksel travmaya karşı bariyer görevi görür, plak kontrolünü sağlar ve ayrıca restorasyon veya ortodontik tedavi gören dişlerin çevresindeki dişeti sağlığının devamlılığına yardımcı olur (Scarano, Barros, Lezzi, Piattelli \& Novaes, 2009).

Günümüze kadar yeterli keratinize dişeti genişliği sağlanmasını amaçlayan çeşitli yöntemler ortaya çıkmıştır. Fakat serbest dişeti grefti yöntemi bu ogmentasyon prosedürleri arasında altın standart olarak değerlendirilmektedir (Dragan, Hotlzman, Karimbux, Morin \& Bassir, 2017; Scarano ve ark., 2009). Bu vaka raporunda da yetersiz keratinize dişeti ve ince dişeti fenotipi bulunan hastaya uygulanan serbest dişeti grefti uygulaması anlatılmaktadır.

\section{Olgu Sunumu}

17 yaşında kadın hasta alt ön bölgede dişetlerinin çok ince olması ve kök yüzeylerinin belirgin olmasının ileride sıkıntı oluşturabileceği şüphesi ile İnönü Üniversitesi Diş Hekimliği Fakültesi Periodontoloji bölümüne başvurdu. Yapılan intraoral muayenede dişeti fenotipi $0,7 \mathrm{~mm}$ ve keratinize dişeti miktarı ise dikey olarak $1,1 \mathrm{~mm}$ olarak belirlendi. Bu veriler ile birlikte hastanın 32-42 numaralı dişler bölgesinde ince dişeti fenotipine ve yetersiz keratinize dişetine sahip olduğu tespit edildi (Resim 1.a). Yapılan radyografik muayenede diş ve çevre dokularında bir problem gözlenmedi (Resim 1.b).
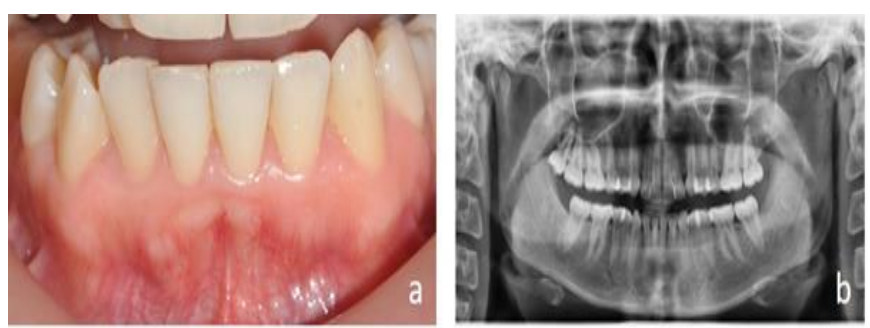

Resim 1. a) İlk muayenedeki klinik görüntü b) İlk muayenede alınan radyografi 


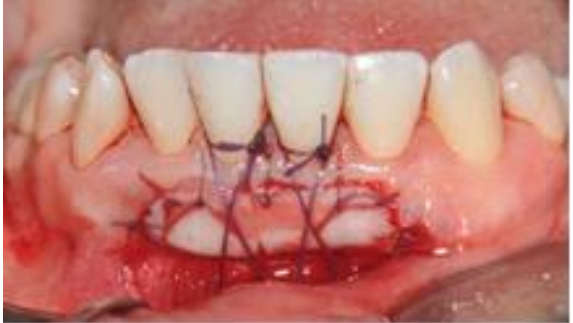

Resim 2. Dişeti greftinin yerleştirilmesi

Yapılan değerlendirme sonrası 32 ve 42 numaralı dişlerin arasında bulunan dişeti bölgesine serbest dişeti grefti uygulanmasına karar verildi. Hasta onam alındıktan sonra ameliyata alındı. Lokal anestezi altında marjinal dişeti kenarın $1 \mathrm{~mm}$ apikalinden olacak şekilde alıcı bölge deepitelize edildi.

Kök yüzeylerinde herhangi bir fenestrasyon/dehisens olmadığı için kök yüzeylerine bir işlem uygulanmadı. Alıcı bölge hazırlandıktan sonra sağ üst palatinal bölgeden $15 \times 6$ $\mathrm{mm}$ boyutunda serbest dişeti grefti alındı. Serbest dişeti grefti, üzerinde herhangi bir düzensizlik olmayacak şekilde düzeltildikten sonra alıcı bölgeye uyumlu olacak şekilde şekillendirildi. Ardından serbest dişeti grefti 6-0 rezorbe olabilen sütur (Pegelak®, Türkiye) kullanılarak alıcı bölgeye adapte edildi (Resim 2).

Donör saha sekonder iyileşmeye bırakıldı. Fakat hem operasyon sonrası kanama kontrolünde hem de iyileşme sürecinde hastanın konforuna katkı sağlaması açısından donör sahaya periodontal pat (Coe-Pak, Japonya) uygulandı. Alıcı bölgeye de serbest dişeti greftinin stabilizasyonuna katkı sağlaması amacıyla periodontal pat uygulandı. Hastaya operasyon sonrası yapması gerekenler anlatıldı. Hastaya klorheksidin içerikli gargara ile analjezik reçete edildi. Operasyondan 7 gün sonra süturların alınması için hastaya randevu verildi.

7. günde serbest dişeti greftinin başarılı bir şekilde alıcı bölgeye adapte olduğu gözlendi. İyileşmede problem olmadığı tespit edildikten sonra süturlar alındı. 45. günde, 3. ayda ve 5. ayda yapılan kontrollerde yeterli keratinize dişeti genişliğinin oluştuğu ve dişeti fenotipinde kalınlaşma sağlandığı gözlendi (Resim 3).

\section{Tartışma}

Keratinize dişetinin periodontal sağlığın devamlıığı için gerekli olup olmadığı günümüze kadar süregelen bir konu olmuştur (Agarwal ve ark., 2015; Mehta \& Lim, 2010; Miyasato ve ark., 1977; Nevins ve ark., 2011). Son zamanlarda periodontal sağlık için tartışılan bu konu, peri-implant sağlık için de tartışma konusu olmuş olup bu konuda da farklı görüşler mevcuttur (Kissa, El Kholti, Laalou \& El Farouki, 2017). Bu vakada alt anterior bölgede keratinize dişetinin eksikliğinin yanında, ince dişeti fenotipi ve kök çıkıntılarının belirgin olması ve ince ve travmaya açık bir dişetinin bulunması nedenleriyle serbest dişeti grefti uygulanmasına karar verildi.
Keratinize dişeti genişliğini arttırmak için çeşitli yöntemler mevcuttur (Bohannan, 1962; Scarano ve ark., 2009). Bu yöntemler arasında serbest dişeti grefti yöntemi keratinize dişeti kazancı olarak daha iyi sonuçlar vermektedir (Cevallos ve ark., 2020; Dragan ve ark., 2017). Fakat bu yöntemin de bazı dezavantajları mevcuttur. Özellikle donör saha olması nedeniyle ikinci bir yara bölgesi oluşması bu dezavantajların başında gelmektedir (Agarwal ve ark., 2015). Serbest dişeti grefti uygulaması ile modifiye apikale pozisyone flep uygulamasını karşılaştıran bir çalışmada serbest dişeti grefti daha başarılı bulunmuştur. Fakat araştırmacılar modifiye apikale pozisyone flep yöntemi ile hedeflenen $2 \mathrm{~mm}$ üzerinde keratinize dişeti genişliğine ulaştıkları için ikincil bir yara bölgesi oluşturmaktansa bu yöntemin tercih edilebileceğini belirtmişlerdir (Bertoldi, Bencivenni, Lucchi \& Consolo, 2007). Fakat bu yöntemin uygulanabilmesi için marjinal dişeti bölgesinde en az 0,5 mm keratinize dişeti bulunması gerektiği belirtilmiştir (Carnio \& Miller, 1999).

Amerikan Periodontoloji Akademisi'nin (AAP) 2015 yılında yaptığı çalıştayda dişeti arttırma işlemlerinde öncelikli olarak subepitelyal bağ doku grefti kullanımını önermektedir (Richardson ve ark., 2015). Bağ doku greftinin uygulanmasında ise koronale pozisyone flep ve tünel yöntemleri arasında başarı açısından farklı sonuçlar alınan çalışmalar mevcuttur (Azaripour ve ark., 2016; Zuhr, Rebele, Schneider, Jung \& Hürzeler, 2014). Başarı faktörü dışında dişeti papilinin bütünlüğünün bozulmaması ve vertikal insizyonlara intiyaç duymaması özellikleri ile tünel operasyonu ile bağ doku grefti uygulanması işlemi ön plana çıkmaktadır (Fahmy \& Taalab, 2018; Papageorgakopoulos, Greenwell, Hill, Vidal \& Scheetz, 2008). Bu vakada tünel operasyonununda oluşabilecek dokunun rüptüre olması veya perforasyonu gibi komplikasyonlar nedeniyle ve de yeterli sulkus derinliğinin de sağlanabilmesi amacıyla serbest dişeti grefti uygulaması tercih edilmiştir. Fakat serbest dişeti grefti yönteminin bağ doku grefti yöntemlerine karşı estetik açıdan dezavantajı bulunmaktadır (Dragan ve ark., 2017). Bu nedenle estetik bölgelerde serbest dişeti greftine alternatif yöntemlerin uygulanması önerilmektedir (Cevallos ve ark., 2020; Kissa ve ark., 2017).

\section{Sonuç ve Öneriler}

Günümüzde keratinize dişeti genişliğinin $2 \mathrm{~mm}$ altında olması periodontal cerrahi uygulanması için tek başına bir sebep olarak değerlendirilmemektedir. Fakat ince dişeti fenotipi bulunması, dişin ortodontik tedavi ile bukkale pozisyonlandırılacak olması, dişetinde çekilme olması gibi risk faktörleri ile bir arada olduğu durumlarda bu risk faktörlerini elimine etmek için dişeti ogmentasyon prosedürlerini uygulamak faydalı olabilir. Klinisyenler, serbest dişeti grefti uygulaması veya diğer ogmentasyon prosedürlerini uygulama yapılacak vakanın özelliklerini göz önüne alarak tercih etmelidir.
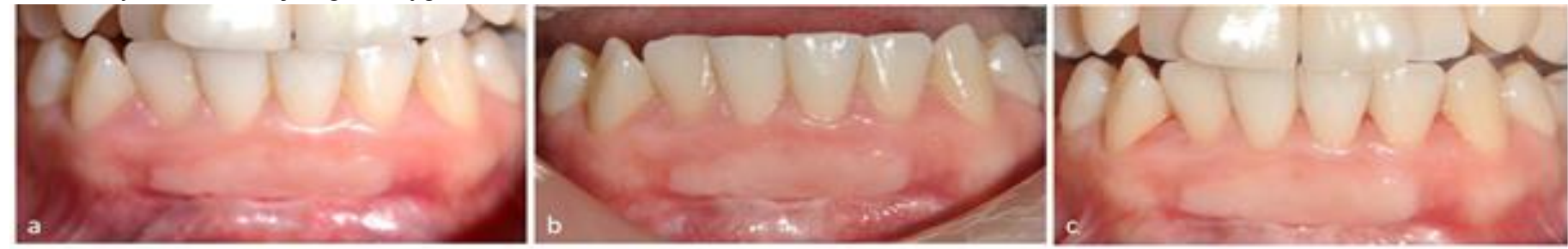

Resim 3. a) 45. gün kontrol b) 3. ay kontrol c) 5. ay kontrol 


\section{Çıkar Çatışması}

Çalışmamızda

bulunmamaktadır.

herhangi bir çıkar çatışması

\section{Finansal Destek}

Çalışmamız için herhangi bir finansal destek alınmamıştır.

\section{Bilgilendirilmiş Onam}

Olgu sunumumuzda yer alan hastamızdan onam alınmıştır.

Hakem Değerlendirmesi

Dış bağımsız.

\section{Yazar Katkıları}

M.A.: Veri Toplama, Literatür Tarama ve Yazım Aşaması C.A.A.: Veri Toplama, Literatür Tarama ve Yazım Aşaması

\section{Kaynaklar}

Agarwal, C., Tarun Kumar, A. B., \& Mehta, D. S. (2015). Comparative evaluation of free gingival graft and AlloDerm $\circledast$ in enhancing the width of attached gingival: A clinical study. Contemporary Clinical Dentistry, 6(4), 483-488. https://doi.org/10.4103/0976237X.169838

Azaripour, A., Kissinger, M., Farina, V. S. L., Van Noorden, C. J. F., Gerhold-Ay, A., Willershausen, B., \& Cortellini, P. (2016). Root coverage with connective tissue graft associated with coronally advanced flap or tunnel technique: a randomized, double-blind, mono-centre clinical trial. Journal of Clinical Periodontology, 43(12), 1142-1150. https://doi.org/10.1111/jcpe.12627

Bertoldi, C., Bencivenni, D., Lucchi, A., \& Consolo, U. (2007). Augmentation of keratinized gingiva through bilaminar connective tissue grafts: a comparison between two techniques. Minerva Stomatologica, 56(1-2), 3-20.

Bohannan, H. M. (1962). Studies in the Alteration of Vestibular Depth I. Complete Denudation. Journal of Periodontology, 33, 120-128.

Carlos, M. C., Muyco, M. M., Caliwag, M. C., Fajardo, J. A., \& Uy, H. G. (1995). The prevalence and distribution of gingival recession among U.E. dental students with a high standard of oral hygiene. The Journal of the Philippine Dental Association, 47(3), 27-48.

Carnio, J., \& Miller, P. D. (1999). Increasing the Amount of Attached Gingiva Using a Modified Apically Repositioned Flap. Journal of Periodontology, 70(9),

1110-1117. https://doi.org/10.1902/jop.1999.70.9.1110

Cevallos, C. A. R., de Resende, D. R. B., Damante, C. A., Sant'Ana, A. C. P., de Rezende, M. L. R., Greghi, S. L. A., \& Zangrando, M. S. R. (2020). Free gingival graft and acellular dermal matrix for gingival augmentation: a 15-year clinical study. Clinical Oral Investigations, 24(3), 1197-1203. https://doi.org/10.1007/s00784019-02983-0

Dragan, I. F., Hotlzman, L. P., Karimbux, N. Y., Morin, R. A., \& Bassir, S. H. (2017). Clinical Outcomes of Comparing Soft Tissue Alternatives to Free Gingival Graft: A Systematic Review and Meta-Analysis. Journal of Evidence-Based Dental Practice, 17(4), 370-380.e3. https://doi.org/10.1016/j.jebdp.2017.05.008

Fahmy, R. A., \& Taalab, M. R. (2018). Modified tunnel technique for management of gingival recession in esthetic zone using acellular dermal matrix versus connective tissue graft. Future Dental Journal. 1-5. https://doi.org/10.1016/j.fdj.2018.12.001

Kissa, J., El Kholti, W., Laalou, Y., \& El Farouki, M. (2017). Augmentation of keratinized gingiva around dental implants. Journal of Stomatology, Oral and Maxillofacial Surgery, 118(3), 156-160. https://doi.org/10.1016/j.jormas.2017.04.003

Lang, N. P., \& Löe, H. (1972). The Relationship Between the Width of Keratinized Gingiva and Gingival Health. Journal of Periodontology, 43(10), 623-627. https://doi.org/10.1902/jop.1972.43.10.623

Lindhe, J., \& Wennström, J. L. (1983). Plaque-induced gingival inflammation in the absence of attached gingiva in dogs. Journal of Clinical Periodontology, 10, 266-276.

Mehta, P., \& Lim, L. P. (2010). The width of the attached gingivaMuch ado about nothing? Journal of Dentistry, 38(7), 517-525. https://doi.org/https://doi.org/10.1016/j.jdent.2010.04.007

Miyasato, M., Crigger, M., \& Egelberg, J. (1977). Gingival condition in areas of minimal and appreciable width of keratinized gingival. Journal of Clinical Periodontology, 4(3), 200-209. https://doi.org/10.1111/j.1600-051X.1977.tb02273.x

Nevins, M., Nevins, M. L., Kim, S.-W., Schupbach, P., \& Kim, D. M. (2011). The use of mucograft collagen matrix to augment the zone of keratinized tissue around teeth: a pilot study. The International Journal of Periodontics \& Restorative Dentistry, 31(4), 367-373.

Papageorgakopoulos, G., Greenwell, H., Hill, M., Vidal, R., \& Scheetz, J. P. (2008). Root Coverage Using Acellular Dermal Matrix and Comparing a Coronally Positioned Tunnel to a Coronally Positioned Flap Approach. Journal of Periodontology, 79(6), 10221030. https://doi.org/10.1902/jop.2008.070546

Richardson, C. R., Allen, E. P., Chambrone, L., Langer, B., McGuire, M. K., Zabalegui, I., ... Tatakis, D. N. (2015). Periodontal Soft Tissue Root Coverage Procedures: Practical Applications From the AAP Regeneration Workshop. Clinical Advances in Periodontics, 5(1), 2-10. https://doi.org/10.1902/cap.2015.140059

Scarano, A., Barros, R. R. M., Lezzi, G., Piattelli, A., \& Novaes, A. B. (2009). Acellular Dermal Matrix Graft for Gingival Augmentation: A Preliminary Clinical, Histologic, and Ultrastructural Evaluation. Journal of Periodontology, 80(2), 253-259. https://doi.org/10.1902/jop.2009.080326

Zuhr, O., Rebele, S. F., Schneider, D., Jung, R. E., \& Hürzeler, M. B. (2014). Tunnel technique with connective tissue graft versus coronally advanced flap with enamel matrix derivative for root coverage: A RCT using 3D digital measuring methods. Part I. Clinical and patient-centred outcomes. Journal of Clinical Periodontology, 41(6), 582-592. https://doi.org/10.1111/jcpe.12178 